\title{
Flexibility and its Discontents: Colquhoun's Critique of the Pompidou Center
}

\author{
JONATHAN OCHSHORN
}

Cornell University

All buildings change or, as Stewart Brand argues, they "learn"-often badly-over time. In fact, a time-based understanding of the life cycle of different building systems is a key component of building flexibility, preventing relatively short-lived ducts and conduit, for example, from being embedded in relatively long-lived structural elements. Yet even taking such advice to heart, making buildings truly flexible is not easy, since both culture and technology change in ways that simply cannot be predicted. This paper focuses on Alan Colquhoun's critique of the Pompidou Center in Paris (1977)-the competition-winning museum designed by Renzo Piano, Richard Rogers, and Gianfranco Franchini (along with Peter Rice of Ove Arup \& Partners)-in order to dig a bit deeper into both objective and subjective aspects of flexibility that relate primarily to size and geometry. Big spaces have been linked to flexibility, freedom, and generic form, i.e., form without particular expressive or articulated qualities that might otherwise, somehow, constrain unanticipated activities. The idea of a generic loft-like space in which anything might happen-a particular and persistent vision of both utopian and dystopian flexibility-shows up in theories of modern architecture in many contexts. Alan Colquhoun, for example, in his 1977 essay, "Plateau Beaubourg," criticizes such values, but his arguments against the Pompidou Centre in Paris remain problematic. In this paper, I examine and critique Colquhoun's attitude toward fixity and flexibility, exterior expression of interior functions, architect-designed user-controlled elements, and the complexity of modern life.

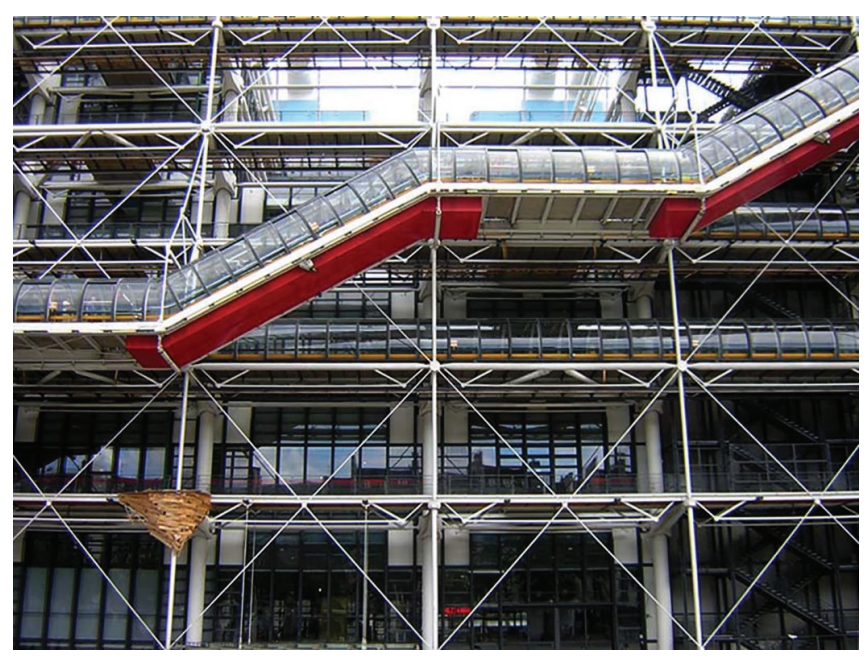

Figure 1. Pompidou Centre, Paris, designed by Richard Rogers and Renzo Piano, 1977. Photo by the author, 2010.

\section{INTRODUCTION}

Architectural flexibility has two meanings: (1) to anticipate and facilitate future change and (2) to permit adaptation as an ongoing operating condition of the building. All buildings must adapt to the future, a future in which some changes are quite predictable-even if their precise content is unclear (e.g., replacement of furniture, painting of walls and ceilings, repair or maintenance of interior and exterior construction, upgraded appliances and mechanical equipment, and so on)-and in which some changes are unexpected and, at least when the building is designed and built, unknown. On the other hand, some buildings must also adapt to ongoing changes as part of their utilitarian functionality: this includes many museums, where new exhibits may well require reconfigured partitions or newly painted walls.

But all buildings change, whether or not these changes are anticipated by their designers. Stewart Brand makes the case that while all buildings "learn," most adapt poorly to changing circumstances: "Almost no buildings adapt well. They're designed not to adapt; also budgeted and financed not to, constructed not to, administered not to, maintained not to, regulated and taxed not to, even remodeled not to. But all buildings (except monuments) adapt anyway, however poorly, because the usages in and around them are changing constantly." Brand quotes the British architect Frank Duffy, who prefers to think of buildings, not as "buildings," but rather as "several layers of longevity of built components," categorized as shell, services, scenery, and set (figure 2). In this formulation, the shell, or structure, ought to survive for the life of the building, whereas services (like HVAC systems) might last 15 years, scenery (such as suspended ceilings or partitions) might last 5-7 years, and set (primarily furniture) may well be moved around or replaced far more frequently. ${ }^{2}$ "Thinking about buildings in this time-laden way is very practical," says Duffy. "As a designer you avoid such classic mistakes as solving a five-minute problem with a fifty-year solution, or vice versa." ${ }^{3}$

Instead of designing buildings that explicitly account for the time-based functions diagrammed by Brand and Duffy, architects often invoke a literal (and short-sighted) ideal of functionalism that fixes in place, and formally articulates, some current idea about the requirements of, and relationships among, specialized rooms and circulation systems, thereby foreclosing the possibility of adapting to future programmatic changes. Critiquing the work of architects Hugo 


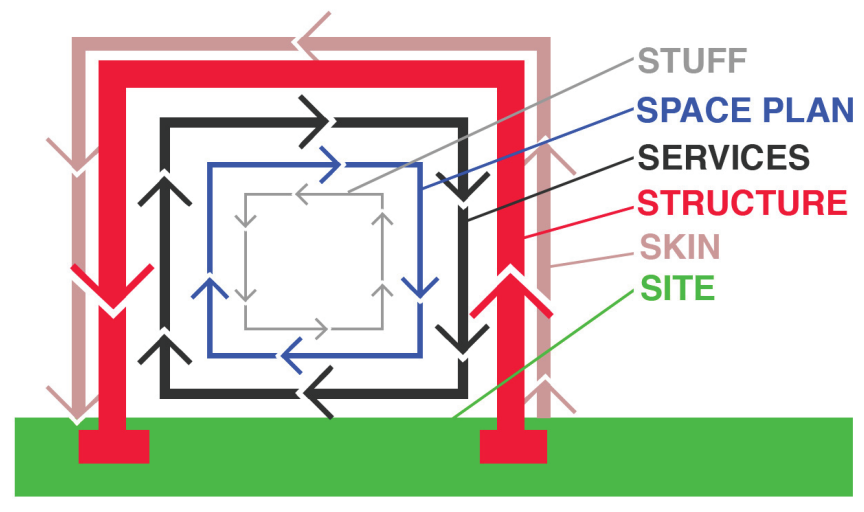

Figure 2. Diagram of time-based building systems, based on Stewart Brand's "shearing layers of change" (How Buildings Learn, p.13) which is based, in turn, on Frank Duffy's categories, but with two more S's and some changed names ("site, structure, skin, services, space plan, and stuff"), each with its own characteristic time-frame for repair, maintenance, or replacement (drawn by the author)

Häring and Hans Scharoun in the 1920s, the German critic and historian Adolf Behne anticipated precisely this problem, arguing that the articulation of different corridor widths in their buildings, based on a biological analogy of "living arteries" that are allowed "to narrow, to shrink, in places where there is less traffic" was actually dysfunctional: "This is all right provided that traffic always follows this same path until the death of the building; that the same conditions prevail as on the first day; in the same way as is the case for blood corpuscles in an organism. But it is wrong, and the functional becomes antifunctional as soon as the traffic finds different conditions-such as through a change of owner or when purpose alters traffic requirements-whereby it could be heaviest in precisely those places where the plan requires it to be lightest."

On the other hand, even accepting the critique of Behne and the advice of Duffy, it's hardly self-evident how to make buildings truly flexible, since both culture and technology change in ways that simply cannot be predicted. This paper focuses on Alan Colquhoun's critique of the Pompidou Center in Paris (1977) - the competition-winning museum designed by Renzo Piano, Richard Rogers, and Gianfranco Franchini (with the structure designed by Peter Rice of Ove Arup \& Partners)-in order to dig a bit deeper into both objective and subjective aspects of flexibility that relate primarily to size and geometry.

\section{BEING BIG}

Some building geometries and dimensions lend themselves to adaptability better than others. This is not to say a single building geometry can be found that can accommodate all the activities encountered in modern society: an apartment house, for example, cannot be expected to easily transform into a museum. Still, within a given context, flexibility can be enhanced, rather than constrained, by planning for the types of activities, and their interrelationships, commonly encountered within that context, rather than designing precisely for the activities programmed at that point in time.

Brand argues, for example, that a mere nine-foot reduction of building width, from 64 feet to 55 feet, constrains flexibility in typical academic buildings: "MIT's Main Building, which is still the core of the campus, is a web of high, narrow wings 64 feet wide-just right for a wide corridor in the middle, with space for a variety of classrooms, laboratories, and offices on each side. (A later MIT building of 55-foot width was found to be inflexibly restrictive.) ${ }^{\prime \prime}$ On the other hand, such anecdotal observations cannot always be verified: many academic buildings seem to provide adequate space for offices and classrooms-even large lecture halls-with dimensions that are quite a bit smaller than Brand's "optimal" 64 feet. ${ }^{6}$

Nevertheless, size matters, a fact that has led various architects to suggest that simply making things bigger solves many problems involving the anticipation of future needs. This is because whereas a larger space can usually accommodate any and all activities that "fit" inside its envelope-even when those activities require less space than is available-a smaller space can never accommodate activities requiring more space than is available. This much is self-evident, although it should be noted that some activities do require a space of a particular size, and would not function well in a space made arbitrarily bigger for the sole purpose of fostering flexibility. One would not, for example, expect a squash court to function properly if the distance between opposing walls was greater (or smaller) than 9.75 meters.

A space that is larger than required may indeed accommodate activities that "fit" within it (like the hypothetical squash court), but in doing so may require modifications, i.e., new or altered partitions, ceiling heights, mechanical/electrical services, and so on. Additionally, changes in occupancy may also trigger building code issues (especially related to fire safety and egress) or structural issues. This type of flexibility therefore comes with a cost, since such modifications may not only be expensive, but also may disrupt activities within the building while being implemented. In fact, the cost may be so great that such modifications are precluded, in which case the space's "flexibility" is to that extent moot.

Robert Venturi suggested that "most buildings should not be designed like a glove that fits every finger exactly, but like a mitten that allows 'wiggle-room'-flexibility-inside." In the same vein, Kari Jormakka recounts an argument between Mies van der Rohe and Hugo Häring in which Häring explained a specific architectural geometry on the basis of a careful functional analysis: "Mies, however, rejected such attempts to optimize shape and told his colleague: 'Hugo, just make your rooms big, then you can do everything in them.' Although Mies is obviously right to a degree," writes 
Jormakka, "it is clear that any room which is equally good for every function is not particularly good for any of them, nor it is [sic] exactly economical." ${ }^{8}$

Here again, a note of caution is needed: while "bigness" is often useful in accommodating unanticipated functions, there is more to functional flexibility than mere size: issues involving acoustical separation, fire safety, accessibility, structural strength, plumbing, daylight, and so on, may well constrain not only the utility but also the flexibility of even the biggest space.

\section{PLATEAU BEAUBOURG}

Big spaces have been linked to flexibility, freedom, and generic form, i.e., form without particular expressive or articulated qualities that might otherwise, somehow, constrain unanticipated activities. The idea of a generic loft-like space in which anything might happen-a particular and persistent vision of both utopian and dystopian flexibility-shows up in theories of modern architecture in many contexts. Alan Colquhoun, for example, in his 1977 essay, "Plateau Beaubourg," criticizes such values, although his arguments against the Pompidou Centre in Paris are problematic in numerous ways.

Fixity and flexibility. In criticizing the building, Colquhoun argues that it does not create "separate spaces with varying degrees of fixity and flexibility" but that instead, the architects "proposed a solution in which the entire building was flexible and which consisted of a series of superimposed and uniform loft spaces. The structure, circulation, and service elements were then pulled to the outside surfaces and used to give interest to facades which otherwise would have been inexpressive. ${ }^{\prime \prime}$ This, however, misrepresents the actual design of Beaubourg; Colquhoun's argument fundamentally confuses fixity with flexibility. How can it be that the "entire building is flexible" when, at the same time, many "service elements" are "pulled to the outside surfaces" where, indeed, they are fixed.

In fact, Beaubourg is similar to all other buildings to the extent that building "services" (stairs, elevators, plumbing fixtures, HVAC ducts, and so on) are necessarily and always fixed in place. That some services are placed on the building's perimeter is hardly unique or revolutionary. Many modern museums have similar plan partis. The former Whitney Museum (now the Met Breuer), built 11 years earlier than the Beaubourg, also consists of large flexible interior spaces (albeit with two columns discretely inserted on each floor) with services-stairs, elevators, utility closets-assigned to a zone on the building's perimeter. That the Whitney's services and loft-like spaces are not "expressed" on its outside facade-its appearance is characterized by formal complexity and idiosyncratic geometry-has no bearing on the actual flexibility of the interior spaces or the relationship of service to served spaces.
There are also mechanical systems within the Pompidou's "flexible" spaces, much like in the gallery spaces of all other museums, contradicting the assertion that "service elements" are all on the outside facade. Similarly, the "structure" is not exclusively "pulled to the outside" as claimed, but only the vertical supports; horizontal trusses below each floor and roof are, as they are in all other buildings, in the spaces that they support and define. In other words, what distinguishes the Pompidou Centre from some other museum schemes is simply that the gallery spaces are larger. That's all. It represents only a quantitative, and not a qualitative, difference.

Exterior expression of interior functions. There is also some confusion in Colquhoun's analysis as to whether various functions can be found inside the building without any form of expression on the outside ("What evidently appealed to the jury was the uncompromising way in which the building interpreted the centre as a supermarket of culture, and gave no spatial or plastic form to the various departments exhaustively specified in the brief. ${ }^{\prime \prime 10}$ ) or whether there actually are no such differentiated functions on the inside, but only "a series of superimposed and uniform loft spaces" (with everything not generically classified as exhibition moved to the outside facade). In fact, as the competition axonometric that is included in Colquhoun's critique clearly shows, all of the programmatic requirements-for things like libraries, restaurants, temporary exhibition spaces, and so on-are accounted for in the plans. In other words, the idea that this is some sort of undifferentiated "supermarket" of culture is misleading: there are many fixed elements that both constrain and enable flexibility, as in any other building. In other words, a truly undifferentiated space, without such necessarily fixed elements (bathrooms, terraces, theaters, meeting rooms, etc.), would simply not function, flexibly or otherwise. Flexibility, like freedom, is enabled by the enforcement of certain constraints.

Colquhoun criticizes what he sees as "architecture as a servicing mechanism" in that "it suggests that architecture should not be conceived with any typology of spaces or human uses, but that these functions should be handed over to the spontaneous forces of life."11 This confuses a feeling, based on Colquhoun's ideological bias against the formal articulation of this building, with what is actually present. All museum spaces are fixed by the architectural design; the spaces at the Beaubourg Centre are no different in that respect. All museums are better or worse at accommodating specific works of art-the art could be big or small, or have any number of display or viewing requirements that are better served in some places than in others. This museum is hardly devoid of "any typology of spaces or human uses"-Colquhoun just doesn't like the type-and in no conceivable way are the functions of viewing and displaying cultural things (art, etc.) "handed over to the spontaneous forces of life." Like all other curated shows in all other museums, there is nothing spontaneous about the exhibitions. 
Critical interest in museum flexibility. The origin of modernist interest in flexible ("all-purpose") museum space was outlined by Ada Louise Huxtable in a 1981 critique: "With a few notable exceptions, the museums of the 1960's leaned heavily toward windowless warehousing, or more correctly, their directors did. ... They asked for, and got, anonymous, all-purpose spaces in blind, bland boxes. ... 'Flexibility,'” Huxtable argued, "puts even more creative strain on the abilities of those who use the spaces than on the original designer. ${ }^{121}$ In other words, flexibility is criticized in two ways: first, as lacking character, and second-for that very reason-requiring acts of compensatory design brilliance in each installation to overcome the inherent blandness of the flexible space itself. In the end, Huxtable concludes that it is not flexibility per se that is a problem-in fact, she finds the Beaubourg Centre "to be a winner, after a rocky and uncertain start"-but rather she finds it problematic when buildings and their contents don't "come together as an integrated esthetic whole." However, Huxtable's two main assumptions about flexibility-that the "blandness" of generic space is a problem and that a "synthesis of art and setting" within such space is a worthy goal-can hardly be taken as self-evident.

In the first case, an alleged lack of character in a building (being "bland" or "generic") is, in fact, a description of a particular type of character. The value of this type of character cannot be determined from the physical characteristics of the architecture; it is not an objective property of a building. For example, when Rem Koolhaas critiques the dystopian experience of twenty-first century malls and airports, he provides little more than a compelling rant, 8,000 words of hyperbolic prose in a single, continuous, 15-page paragraph describing what he calls Junkspace-"the product of an encounter between escalator and air-conditioning, conceived in an incubator of Sheetrock. ${ }^{113}$ Arguments of academic critics or casual users only confirm that opinions about such things vary, exposing the subjectivity of such judgments and rendering any supposedly definitive and objective conclusion moot (compare, for example, Colquhoun and Huxtable on the merits of the Pompidou Center).

In the second case, it is self-evident that any alleged synthesis between art and setting depends not only on the subjective appraisal of whether, in fact, a particular art installation "fits" in the space but, more importantly, what particular art is selected, and what art cannot even be considered, based on characteristics of the space. Wright's Guggenheim Museum in New York serves as the most famous example of this dilemma: "The building asserts itself with great force,' says Thomas Messer, a former director of the Guggenheim. 'If one doesn't succeed, the building shows off the work negatively, and if one does succeed, the building takes the credit."' Some artists, like Dan Flavin, have created successful installations specifically for the idiosyncratic space, while others in "the artistic community were, and still are, divided. ... A group of artists led by Robert Motherwell and Willem de Kooning had protested against the design.,"14
Architect-designed user-controlled elements. Colquhoun, in his critique of the Pompidou Center, conflates the "free plan" with flexibility, suggesting that objects fixed in place but "freely" composed are therefore somehow flexible. "Flexibility," he writes, "is also an idea that belongs to the Modern Movement as a whole, but its interpretation as literal adaptability, as opposed to the idea of an object whose parts, though fixed, are freely related according to pragmatic requirements, is one of those separate streams into which modern architecture has developed in more recent years." ${ }^{15}$

He goes on to argue that flexibility implies having "usercontrolled" and moveable items within a fixed structure: "The elements which can change must not only be able to be manipulated by the user, but must be seen to be independent of the fixed elements of the design. They belong to a class of elements which can be rearranged at random, without distorting the generality and intelligibility of the support structure itself." But this argument raises more questions than it answers. First, who is this "user"? Second, why must flexibility consist of "elements" that can be "randomly" moved around? This is, of course, possible, but hardly necessary, since partitions for exhibits can equally well be constructed and demolished from ordinary construction materials-they need not be part of some "system."

In the case of museum exhibit design, the "user" is not the general public, but rather museum staff together with exhibition designers-these users organize museum space for exhibits whether or not the architecture comprising the museum consists of a series of traditional and interconnected rooms or undifferentiated loft-like space. In other words, the idea that flexibility requires the latter (loft-type space) rather than the former (traditional rooms) abstracts from the actual content and intentions underlying the particular exhibits to be mounted. For certain types of art or installations, an undifferentiated loft-type space would create enormous obstacles for an appropriate display, while traditional interconnected rooms would similarly create impossible constraints for other types of art and installations. Flexibility is a function, not just of spatial typologies, but also of internal content, i.e., of the art itself. In fact, Colquhoun's vision is no more than the cliché of architect-designed flexibility that insists that the building must be read ("must be seen") as comprising architect-designed fixed elements creating an order within which moveable elements can be arranged by the "user," but only within the system specified, in advance, by the architect. In this way, the architect's heroic status persists: any future change remains integral to the design in the form of moveable elements that are part of an architect-designed system.

Complexity of modern life. Colquhoun argues that "the philosophy behind the notion of flexibility is that the requirements of modern life are so complex and changeable that any attempt on the part of the designer to anticipate them 
results in a building which is unsuited to its function, and represents, as it were, a 'false consciousness' of the society in which he operated. ${ }^{\prime \prime 6}$ In other words, architects actually can "anticipate" future changes and design buildings accordingly, but doing so would render the building unsuitable for its current occupation. In this puzzling vision of flexibility, the architect not only is able to anticipate (predict) what is necessary for some unspecified future time, but freezes that future-oriented design, making it unsuitable for the present, and, by implication, unsuitable for any other "future" that is different from the time for which it was designed. In this way, Colquhoun actually discounts the need for buildings to adapt.

Colquhoun also argues that the need for flexibility derives from two characteristics of modern society: complexity and constant change. But flexibility has nothing to do with "complexity," only with change. And an architect need not (in fact, cannot) predict the future in order to create a flexible design. Rather, designers anticipate, and account for, change precisely because future needs and future technologies are unknown.

\section{CONCLUSION}

The process of accounting for, rather than predicting, change forces architects to consider several factors. First, the life-cycle of building systems over time must be taken into account. Second, the constraints and opportunities provided by building geometry must be evaluated, in particular, the dimensions between fixed elements of the building that might facilitate, or inhibit, future arrangements of rooms and spaces. Third, it is often useful to make things bigger than what might be currently required. Aside from Venturi's advice to allow some "wiggle-room" in buildings-to increase building dimensions-flexibility is fostered when other building elements are also increased in size or capacity: designing a structural system to resist greater loads not only permits future changes in interior finishes (e.g., replacing carpet with ceramic tile) or roofing systems (e.g., replacing a standard single-ply system with a vegetated roof), but, more importantly, permits changes in occupancy group or building function (e.g., adding storage areas, replacing residences with offices, or replacing classrooms with libraries, etc.). On the other hand, there are several factors that militate against unfettered flexibility, briefly outlined below:

Plumbing. Relatively fixed building systems such as plumbing (bathrooms, kitchens) and building service systems that have been embedded-contrary to the advice implied in the Brand/Duffy diagram (figure 2)-within the building's structure, make it difficult for such systems to be moved or increased (in the first case), or repaired or replaced (in the second case).
Fire safety. Requirements for compartmentation, fire-rated assemblies, egress, sprinklers, maximum floor area, and building height-all elements of fire safety-are based on particular combinations of occupancy groups and construction types, so that the flexibility to change occupancy, or even to adjust the position of and relationships between different occupancies, is contingent upon how the building was initially constructed.

Zoning. The idea that a building has the potential to be almost infinitely flexible-that it can function, as Rem Koolhaas argues, like a city within a city ${ }^{17}$-both abstracts from the constraints of zoning regulations and misunderstands the nature and purpose of cities. In the first case, modern zoning simply prevents certain occupancies in certain locations, radically limiting the ability of any given building to accommodate multiple, and unspecified, functions. In the second case, modern cities require many different types of buildings which cannot usefully be integrated within a single structure. Jane Jacobs, a fan of capitalist cities, understood that low-value spaces are different from high-value spaces; that they emerge over time as neighborhoods decay and their buildings are repurposed. ${ }^{18}$ Cities thrive on poverty and wealth; one cannot create a single structure to accommodate both. A supermarket, replacing smaller markets, is not a city; an office building replacing smaller offices, is not a city. A building getting bigger represents a quantitative change with respect to its relationship to the city; not a qualitative one.

The Pompidou Center-Colquhoun's Plateau Beaubourg-is interesting not because it pushed the envelope of flexibility, but because it triggered so much debate about the subject, much of it a critique of expression masquerading as a critique of flexibility. Like all museums, it suits certain installations and not others; and like all museums, each new installation requires some imaginative design and construction. Colquhoun did not consider the time-based life cycles of "site, structure, skin, services, space plan, and stuff," (figure 2) and their implications for building design and flexibility. In fact, the placement of services-escalators and mechanical ducts-on the building exterior may allow Center Pompidou galleries to remain open as they are repaired or replaced. However, "the original idea of the architects ... to have the nuts-and-bolts inner workings of the museum on the outside ... meant much of the structure, which closed for an $€ 88 \mathrm{~m}$ refurbishment between 1998 and 2000 [and is undergoing another substantial renovation in 2018-2020], suffered from its continual exposure to the elements. ${ }^{19}$ Whether the radical decision to place certain services on the outside of the building makes it flexible, i.e., facilitates adaptation to future contingencies, remains an open question. 


\section{ENDNOTES}

1 Stewart Brand, How Buildings Learn: What Happens After They're Built (New York: Penguin Books, 1994), 2.

2 Frank Duffy quoted in Brand, How Buildings Learn, 12.

3 Duffy quoted in Brand, How Buildings Learn, 17.

4 Adolf Behne, The Modern Functional Building, trans., Michael Robinson (Santa Monica, CA: Getty Research Institute for the History of Art and the Humanities 1996-original written in 1923 and originally published in German in 1926), 129.

5 Brand, How Buildings Learn, 177.

6 At the institution where I teach, classroom/office buildings seem perfectly adequate (and flexible) with dimensions ranging from 45 to 55 feet in width.

7 Hans Ulrich Obrist, "Re-Learning from Las Vegas," interview with Venturi and Scott Brown, in Content, ed., Brendan McGetrick (KöIn; London; et al.: Taschen, 2004), 155.

8 Kari Jormakka, "The Manhattan Project," in Organizing for Change/Space: Integrating Architectural Thinking in Other Fields, ed., Michael Shamiyeh (Basel: Birkhäuser, 2007), 118.

9 Alan Colquhoun, “Plateau Beaubourg," Architectural Design 47, no. 2 (1977): 98.

10 Colquhoun, 98.

11 Colquhoun, 100

12 Ada Louise Huxtable, "The Legacy of Museum Design of the 1960's," New York Times, November 29, 1981. http://www.nytimes.com/1981/11/29/arts/architecture-view-the-legacy-of-museum-design-of-the-1960-s.html.

13 Rem Koolhaas, “Junkspace," October 100 (Spring 2002): 175.

14 Ultan Guilfoyle, "Architecture: Extension of a New York Controversy: The Guggenheim is No Ordinary Museum," The Independent, July 29, 1992. https://www.independent.co.uk/arts-entertainment/art/news/ architecture-extension-of-a-new-york-controversy-the-guggenheim-is-noordinary-museum-ultan-1536218.html.

15 Colquhoun, "Plateau Beaubourg," 100.

16 Colquhoun, "Plateau Beaubourg," 100.

17 "The Equitable is promoted as a 'City in itself, housing 16,000 souls.' That is a prophetic claim that unleashes one of Manhattanism's most insistent themes: from now on each new building of the mutant kind strives to be 'a City within a City.' This truculent ambition makes the Metropolis a collection of architectural city states, all potentially at war with each other." Rem Koolhaas, Delirious New York: A Retroactive Manifesto for Manhattan (New York: Montacelli Press, 1994-originally published 1978), 88-89.

18 See, in particular: Jane Jacobs, The Death and Life of Great American Cities (New York: Vintage, 1961); and Jane Jacobs, The Economy of Cities (New York: Random House: 1969).

19 Kim Willsher, "Pompidou Centre Gets a f90m Facelift 40 Years On," The Guardian, January 14, 2017. https://www.theguardian.com/world/2017/jan/15/ pompidou-centre-90m-facelift-40-years. 